\title{
Geochemical and paleomagnetic evidence for the occurrence of "missing" sapropels in eastern Mediterranean sediments
}

\author{
P. J. M. van Santvoort and G. J. de Lange \\ Department of Geochemistry, Institute of Earth Sciences, Utrecht University, Utrecht, Netherlands
}

\author{
C. G. Langereis and M. J. Dekkers
}

Paleomagnetıc Laboratory, Institute of Earth Sciences, Utrecht University, Utrecht, Netherlands

\section{Paterne}

Centre des Faibles Radioactivités, Laboratoire Mixte CNRS-CEA, Gif-sur-Yvette, France

\begin{abstract}
The cyclic occurrence of sapropels appears to be associated with maxima in the $65^{\circ} \mathrm{N}$ summer insolation target curve. Studies of the most recent sapropel have revealed extensive oxidation of organic matter or even the complete removal of this unit. Geochemical and magnetic signals allow for the detection of such a "missing" sapropel. In older sediments, these signals are altered by ongoing diagenetic processes. An important parameter to reveal missing sapropels is $\mathrm{Ba}$. Elevated concentrations of $\mathrm{Ba}$ are always found in visible sapropels, and even after oxidation of part of the sapropel, the initial Ba profile remains visible. We use this tool to trace down missing sapropels in KC01B, a 37-m Kullenberg core from the Calabrian Ridge, eastern Mediterranean. At least 8 of 11 sampled intervals around insolation maxima contain evidence of a completely oxidized sapropel: $\mathrm{Ba}$, trace metal distributions, and magnetic parameters are similar to those observed around visible sapropels.
\end{abstract}

\section{Introduction}

Eastern Mediterranean sediments are characterized by an alternation of organic-poor hemipelagic, (light) brown sediments and organic-rich $(>2 \%$ organic carbon), dark olive-green sapropels. Sapropels are not only found in sediments below the present-day sea floor but also in uplifted marine sections on-land which date back to the Miocene [e.g. Hilgen, 1991; Hilgen et al., 1993, 1995; Lourens, 1994; Lourens et al., 1996; Van Os et al., 1994; Krijgsman, 1995]. The cyclic occurrence of sapropels appears to be associated with climatic changes. All versions of the orbital hypothesis of climatic change predict that the obliquity of the Earth's axis and the precession of the equinoxes are the underlying controlling variables that influence climate through their impact on planetary insolation [Berger and Loutre, 1992]. Initially, the occurrence of sapropels was inferred to be related to minima in the precession index [Rossignol-Strick, 1983, 1985; Prell and Kutzbach, 1987; Hilgen, 1991]. Lourens et al. [1996] used the $65^{\circ} \mathrm{N}$ summer insolation target curve, calculated from the astronomical solution La90 [Laskar, 1990; Laskar et al., 1993] with present-day values for the dynamical ellipticity of the Earth and tidal dissipation by the Sun and Moon. A 3-kyr time lag between maxima in summer insolation and sapropel midpoints is introduced for the construction of climatic proxy time series. This results in the best fit with the geological record.

Sapropels are not found at each maximum in the insolation target curve. The absence may be caused by climatic conditions

Copyright 1997 by the American Geophysical Union.

Paper number 97PA01351.

0883-8305/97/97PA-01351\$12.00 during maxima that were of different intensities which therefore did not always lead to sapropel formation. Alternatively, it is possible that a sapropel was deposited initially but has subsequently disappeared. Studies of the most recent sapropel have shown that extensive oxidation of organic material resulted in thinning [De Lange et al., 1989; Pruysers et al., 1993; Van Santvoort et al., 1996] or even complete removal of this sapropel unit [Higgs et al., 1994; Thomson et al., 1995]. Such "missing" sapropels are most readily detected by studying geochemical parameters like $\mathrm{Ba}$ and other redox-sensitive elements like $\mathrm{Fe}$ and Mn.

Postdepositional changes in the sediment also cause the mobilization and precipitation of Fe-minerals and influences therefore the magnetic parameters in the sediment [e.g., Van Hoof et al., 1989; Verosub and Roberts, 1995]. Mineral magnetic parameters, including intensity anhysteretic remanent magnetization (ARM), natural remanent magnetization (NRM), and initial magnetic susceptibility $\left(\chi_{\text {in }}\right)$, display a distinct signature with respect to sapropels [Dekkers et al., 1994; Langereis et al., 1997]. Consequently, these parameters can be used as indicators of missing sapropels, even if sapropelic lithology is no longer visible.

In this paper, we present the results of a study of sediments from a 37-m eastern Mediterranean Kullenberg core (KC01B) with a maximum age of 1.1 Myr. On the basis of results from samples taken at 10-cm intervals [Dekkers et al., 1994; langereis et al., 1997], eleven intervals that coincide with maxima in the insolation target curve have been sampled in detail. The diagenetic features around the most recent and an older sapropel are discussed, and a combination of geochemical and magnetic parameters has been used to trace missing sapropels in the sediments of core $\mathrm{KCO} 01 \mathrm{~B}$. 


\section{Material and Methods}

\section{Sapropel Nomenclature}

Under the conventional sapropel nomenclature system, sapropels are continuously numbered from $\mathrm{Sl}$ in the Holocene, continuing with increasing $S$ numbers down the sequence [e.g., Ryan, 1972]. This method gives problems in case of discovery of new sapropels between already classified ones. Since it was noticed that sapropels were correlated to peaks in the precession index, Hilgen [1991] proposed a numbering scheme based on naming sapropels after their correlative peak of the precession index beginning from the Holocene. Lourens et al. [1996] demonstrated that it was better to use the insolation curve rather than precession index for the correlation of sapropels and the climate cycle. In this paper we will follow the method of Langereis et al. [1997] who adapted the Hilgen [1991] method to the Lourens et al. [1996] findings: Maxima in the insolation curve are even-numbered, starting from the Recent, while minima are odd-numbered. Observed sapropels are denoted by an uppercase " $\mathrm{S}$ " and missing sapropels are denoted by a lowercase "s". Sapropel S4, for example, becomes Si10, and a missing sapropel near maximum 14 becomes si14. When new sapropels are identified, only the lowercase "s" needs to be changed, and renumbering of existing sapropels is not necessary.

\section{Sediment, Sampling, and Chronology}

Kullenberg core KCO1B (37 m) was recovered on the Pisano Plateau, Calabrian Ridge (Figure 1), during the 1991 Mast-I cruise with the $R / V$ Marion Dufresne. Twelve sapropels are recognized, starting with Sil0 (S4), and several tephra layers were also found. In some cases it is difficult to visually distinguish a tephra layer from a sapropel because color and texture can be similar. Initial sampling, both for geochemical and paleomagnetic purposes, took place at $10-\mathrm{cm}$ intervals. On the basis of the Ba profile and the insolation target curve (Figure 2), 11 intervals have been sampled in more detail $(0.5$ to $1.5-\mathrm{cm}$ resolution).

Similar studies were conducted on box cores UM15, UM26, and UM35 (Figure 1) that were collected during the 1994 Palaeoflux cruise of $R V$ Urania. The latter cores contain sequences that are typical for the eastern Mediterranean: oxic sediments on top, and a dark brown marker bed that is underlain by a sapropel ( $\mathrm{Si} 2)$. It should be noted that UM15 does not contain a complete sapropel sequence.

In accordance with Langereis et al. [1997], sapropels and some proposed missing sapropels are used in the correlation to the insolation curve. The oxygen isotope record was tuned to the ice sheet model of Imbrie and Imbrie [1980]. The differences between the oxygen isotope curve (tuned to the ice sheet model) and the sapropel pattern (tuned to the La90 $65^{\circ} \mathrm{N}$ summer insolation curve) are generally small, typically ranging from 0 to $5 \mathrm{kyr}$ and averaging $2 \mathrm{kyr}$. We emphasize that both results have been independently derived. A more elaborate discussion is given by Langereis et al. [1997].

\section{Chemical Analyses}

Samples were freeze-dried and finely ground in an agate mortar. After digestion in a mixture of hydrofluoric, nitric, and perchloric acids, final solutions were made up in $1 \mathrm{~N} \mathrm{HCl}$ and were analyzed by inductively coupled plasma emission spectrometry (ICPES) on a Perkin Elmer Optima 3000. The quality of the ICPES analyses was monitored by the inclusion of laboratory and international standards. The error in the analyses was $<3 \%$ for major elements and $<7 \%$ for the trace elements. All

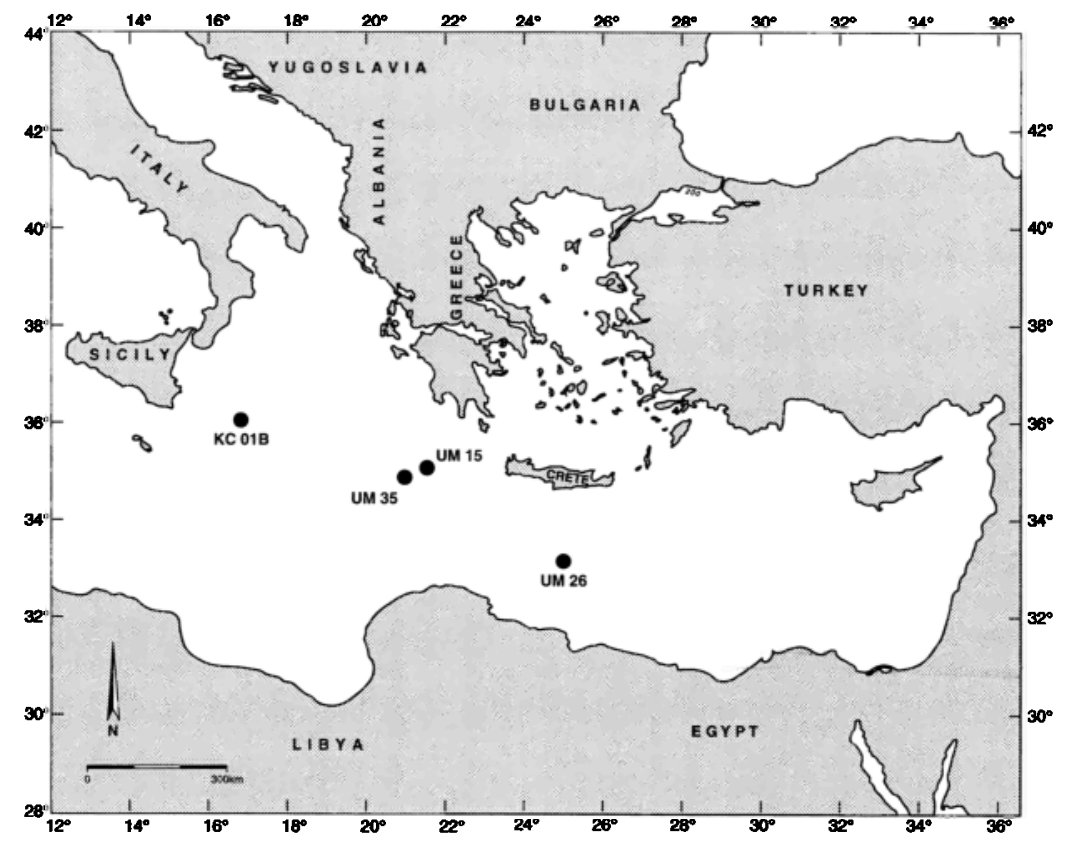

Figure 1. Locations of the cores used in this study. Core KC01B was taken at $36^{\circ} 15.2^{\prime} \mathrm{N}, 17^{\circ} 44.3^{\prime} \mathrm{E}, 3643-\mathrm{m}$ water depth; station UM15 is at $35^{\circ} 17.4^{\prime} \mathrm{N}, 2^{\circ} 24.8^{\prime} \mathrm{E}, 3307 \mathrm{~m}$; UM26 is at $33^{\circ} 23.6^{\prime} \mathrm{N}, 25^{\circ} 00.9^{\prime} \mathrm{E}, 2160 \mathrm{~m}$; and UM35 is at $35^{\circ} 11.0^{\prime} \mathrm{N}, 21^{\circ} 12.54^{\prime} \mathrm{E}, 2670 \mathrm{~m}$. 

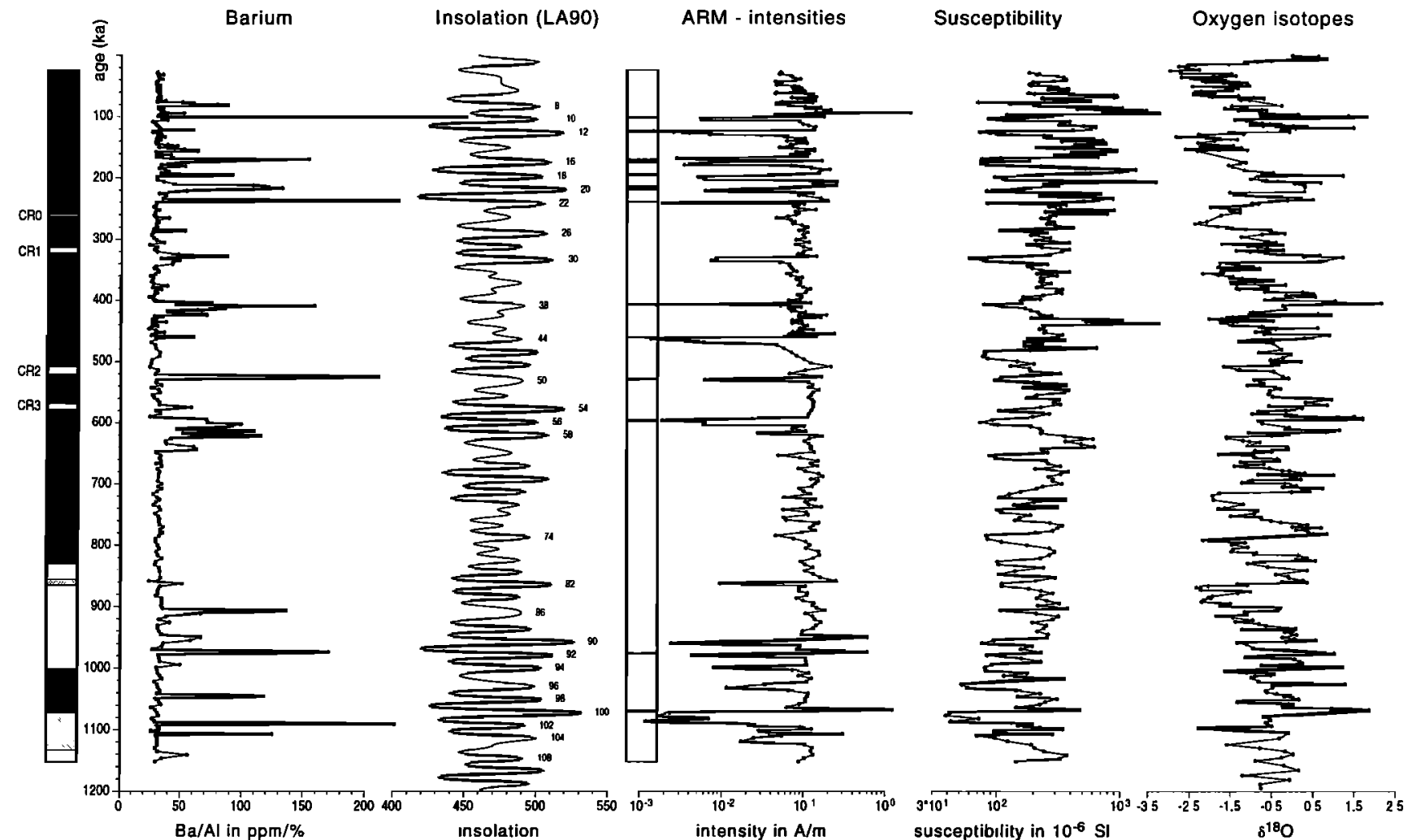

Figure 2. Mineral magnetic records (anhysteretic remanent magnetization (ARM) and $\chi_{\text {in }}$ ) and Ba (normalized to Al) of core KC01B compared with the insolation target curve of Laskar [1990]. Visible sapropels are indicated in the stratigraphic columns. No natural remanent magnetization (NRM) data are plotted because the profile is identical to the ARM plot.

measured concentrations, for both major and trace elements, are well above the limit of detection. Selenium was measured by hydride generation atomic absorption spectrometry (AAS) using a Perkin Elmer 3100 AAS in combination with a Perkin Elmer flow injection analyses system (FLAS) mercury/hydride chemifold and an autosampler. The analytical error is $<5 \%$ for concentrations $>3$ $\mathrm{ppb}$ and up to $50 \%$ at the $0.1-\mathrm{ppb}$ level.

Organic carbon was measured on a Fisons Instruments nitrogen carbon sulphur (NCS) NA1500 analyzer using dry combustion at $1030^{\circ} \mathrm{C}$. Inorganic carbon, as carbonate, was removed before analysis by shaking the sample for 24 hours in 1 $N \mathrm{HCl}$. This procedure was repeated once to ensure that all inorganic carbon had been removed. After drying at $80^{\circ} \mathrm{C}$, the sample was ground in an agate mortar. International and in-house standards were used to check the accuracy of the method. Standard deviations of standards and sample duplicates were always $<1.5 \%$.

To obtain the reducible fraction of the samples, a solution of 1 $M$ hydroxylamine hydrochloride in $25 \%$ acetic acid was used with $1 \mathrm{~g}$ of powdered sediment [Chester and Hughes, 1967]. The leachate was analyzed by ICPES.

Two powdered samples were analysed by X-ray diffraction (Philips PW1700) to obtain the mineralogical composition of the sediment. To correct concentrations, obtained by ICPES and AAS, for carbonate dilution, the measured concentrations were normalized by the $\mathrm{Al}$ concentration and were subsequently multiplied by the average $\mathrm{Al}$ content of the sediment. All elements reported here, except $\mathrm{Ca}$, are corrected in this way.

\section{Paleomagnetic Analyses}

The magnetic variables used in the present study are NRM, $A R M$, and $\chi_{\text {mn }}$. It was not possible to use the high-resolution samples for paleomagnetic analyses due to the small amount of sample available. The presented magnetic data are the results from samples taken at $10-\mathrm{cm}$ intervals, which will be compared with the high-resolution geochemical results.

An ARM was imparted by subjecting samples to an alternating field (AF) which decays from $100 \mathrm{mT}$ to zero, while a bias field of $30 \mu \mathrm{T}$ is imposed. The ARM value is an estimate of the amount of magnetizable material present in the sample [e.g., Levi and Banerjee, 1976]. In particular, fine-grained single domain magnetite has a strong ARM signal and will mainly determine the ARM value of the sample. The NRM intensity reported is that after $\mathrm{AF}$ demagnetization at $20 \mathrm{mT}$. At this demagnetization level, the unstable "viscous" part of the NRM has been demagnetized in these samples. Note that the NRM intensity depends not only on the concentration and type of magnetic minerals present but also on the intensity of the geomagnetic field at the time of NRM lock-in. The low-field magnetic susceptibility is the magnetic moment of a sample measured in a small magnetic field. In contrast to remanent magnetizations that are carried by ferrimagnetic of imperfect ferromagnetic minerals (e.g., ARM or NRM), paramagnetic (iron-bearing silicates like clay minerals, micas, amphiboles, and pyroxenes) and diamagnetic minerals (quartz, carbonates, feldspars) contribute to $\chi_{\mathrm{In}} . \mathrm{NRM}$ and ARM intensities were measured with a vertical $2 \mathrm{G}$ 
Enterprises superconducting SQUID magnetometer or with a digital Geofizica Brno JR3 spinner magnetometer. Low-field magnetic susceptibility was measured with a Geofizica Brno KLY-2 susceptibility bridge (operating frequency $980 \mathrm{~Hz}$, peak field $0.3 \mathrm{mT}$ ).

\section{Results and Discussion}

\section{Oxidation of the Most Recent Sapropel, Si2}

Sapropels are geochemically characterized by high concentrations of organic carbon, $\mathrm{Ba}$, and $\mathrm{S}$. Barium is mainly present as barite [e.g., Thomson et al., 1995] and displays a "quasi-Gaussian" curve (Figure 3). This means that the $\mathrm{Ba}$ concentration displays a gradual increase starting at $32 \mathrm{~cm}$ and a gradual decrease at ending at $14 \mathrm{~cm}$ depth. Iron sulphides, with pyrite as the main sulphur phase, and organically bound $S$ contribute to the high sulphur concentrations in the sapropels [Pruysers et al., 1993; Passier et al., 1996] (Figure 3). Reduced S-species are formed during, or briefly after, deposition of a sapropel, when anoxic conditions (i.e., sulphate reduction) prevail. In reaction with $\mathrm{Fe}$-oxyhydroxides or dissolved $\mathrm{Fe}^{2+}$, these can form Fe-sulphides, not only in, but also below, the sapropel [Passier et al., 1996]. Note that in this paper, Feoxyhydroxides are a general term for Fe-oxides, Fe-hydroxides, and everything in between these two end-members.

Studies of the most recent sapropel have shown that extensive oxidation of organic material has resulted in thinning of this sapropel unit [De Lange et al., 1989; Pruysers et al., 1993; Higgs et al., 1994; Thomson et al., 1995; Van Santvoort et al., 1996]. The oxidation of the sapropel can be described by a progressive downward moving oxidation front [De Lange et al., 1989; Pruysers et al., 1993; Thomson et al., 1993, 1995; Van Santvoort et al., 1996], that was developed by Wilson et al. [1985, 1986] to explain the formation of metal-rich layers in turbidites.
Immediately after sapropel formation ceases, oxygen starts to diffuse down into the sediment. Oxygen is consumed in the oxidation process of organic material and reduced species of the solid phase, such as pyrite, as well as in oxidizing reduced $\mathrm{Fe}$ and $\mathrm{Mn}$-species in the pore water. Below the level where oxygen is present, decomposition of organic material takes place by reduction of nitrate and solid phase $\mathrm{Fe}-$ and $\mathrm{Mn}$-oxyhydroxides. The latter process releases $\mathrm{Fe}^{2+}$ and $\mathrm{Mn}^{2+}$ to the pore water. After upward diffusion, these species are reprecipitated as oxyhydroxides when oxic pore waters are reencountered. Dissolved Fe precipitates at slightly lower oxygen concentrations than $\mathrm{Mn}$ so that the solid phase Fe peak is always located below the Mn peak (Figure 3). The Fe peak is found just below the transition of organic-poor to organic-rich sediment, while the Mn peak is found just above this level. When the downward flux of oxygen is larger than the upward flux of reductants, the oxidation front (the level at which oxygen becomes depleted) will move down, thus oxidizing more of the sapropel. The initially rapid downward movement of the front decelerates with time and forms Fe- and Mn-oxyhydroxide peaks of characteristic shape [e.g., Wilson et al., 1985, 1986] (Figure 3).

In addition to the Mn peak that is formed by the downward moving oxidation front (maximum at $223 \mathrm{~mm}$ in UM26), another peak is observed, a few centimeters above this diagenetic peak, at $155 \mathrm{~mm}$ (Figure 3). The upper peak is thought to mark the end of sapropel formation when the bottom water was reoxygenated [Higgs et al., 1994; Thomson et al., 1995; Van Santvoort et al., 1996]. Either an upward moving $\mathrm{Mn}$ peak was fixed in its position or dissolved $\mathrm{Mn}$ precipitated from the water column. Mackensen et al. [1993] observed a fluffy, organic-rich layer in the South Atlantic Ocean, in which organic material was readily oxidized, leading to large concentration gradients over the sediment-water interface. In this way, pore water gradients would be independent from the redox state of the bottom water, and

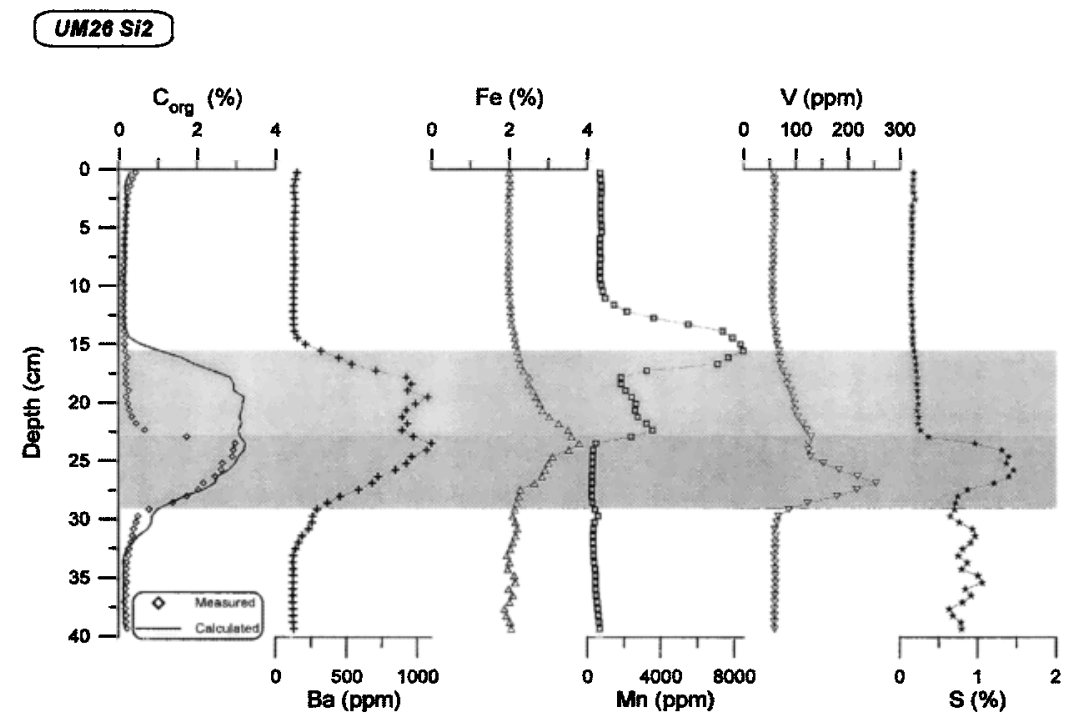

Figure 3. Concentration versus depth profiles of measured (diamonds) and calculated (solid line) organic carbon, $\mathrm{Ba}, \mathrm{Fe}, \mathrm{Mn}, \mathrm{V}$, and $\mathrm{S}$ for $\mathrm{Si} 2$ from core UM26. Solid phase $\mathrm{Ba}, \mathrm{Fe}, \mathrm{Mn}$, and $\mathrm{V}$ are normalized to $\mathrm{Al}$ and multiplied by the average $\mathrm{Al}$ content to minimize the dilution effect by $\mathrm{CaCO}_{3}$. The part of the sapropel that is visible at present is indicated by the darker shaded area. The oxidized part of the initial sapropel, obtained from the calculated organic carbon values, is indicated by the lighter shaded area. 
oxygen depletion in the deep water is unnecessary. However, we consider the low-oxygen scenario to be the most likely option.

Depending on the oxygen concentration of the deep eastern Mediterranean water, the organic carbon flux to the seafloor, the sediment accumulation rate, and the bioturbation depth, some part of a sapropel will usually be oxidized. When the diffusion path of oxygen becomes too long (e.g., due to a high sedimentation rate) or when the organic carbon flux increases, the oxidation front stops moving downward and the remaining part of the sapropel will be preserved. In extreme cases, the entire sapropel can be oxidized, leaving no visible traces of the sapropel [Higgs et al., 1994; Thomson et al., 1995]. Only the use of geochemical and magnetic parameters can reveal the former presence of such a sapropel.

Sediments with a high organic carbon content, including sapropels, generally are reported to contain higher concentrations of trace metals relative to the surrounding sediments [Calvert, 1983; Sutherland et al., 1984; Calvert et al., 1985; Ten Haven et al., 1988; Pruysers et al., 1991]. Most of these elements are associated with the organic material, but Fe-oxyhydroxides may also contain considerable amounts of trace metals. On oxidation of the organic-rich layers, some metals, including $\mathrm{Ni}, \mathrm{Zn}$, and $\mathrm{As}$, become associated with $\mathrm{Fe}$ - and Mn-oxyhydroxides, either by adsorption or by coprecipitation [e.g., Hem et al, 1989]. Therefore a positive correlation between the $\mathrm{Fe}$ - and $\mathrm{Mn}$-content on one side and trace metal concentrations on the other is often found in the oxic sediments above sapropels.

$\mathrm{Se}, \mathrm{Cu}, \mathrm{V}, \mathrm{Sb}$ and $\mathrm{Zn}$ are continuously remobilized in the oxic environment and maintain concentration maxima in the vicinity of the oxidation front [Thomson et al., 1993]. Because $V$ has been analyzed in all intervals, this element, which represents the group mentioned above, will be discussed in more detail. Under oxic conditions, $\mathrm{V}$ behaves in a way that is similar to $\mathrm{Fe}$, and is adsorbed as $\mathrm{H}_{2} \mathrm{VO}_{4}^{-}$[Trefry and Metz, 1989]. A second, often larger $\mathrm{V}$ peak is generally observed within the sapropel and consists of a reduced, relatively immobile species (Figure 3 ). The formation of this peak could be related to the oxyanion that diffused from the seawater into the anoxic pore water. Reduction results in the formation of a reduced $\mathrm{V}$-species that is immobilized by an as yet unknown mechanism [Emerson and Huested, 1991].

A good correlation between organic carbon and $\mathrm{Ba}$ is often observed in organic rich sediments [Calevert 1983; Calvert and Fontugne, 1988; Klinkhammer and Lambert, 1989] and in sediment trap data [Dymond et al., 1992]. This led to the assumption that $\mathrm{Ba}$, which is present as biogenic barite, can be used as a paleoproductivity proxy [Dymond et al., 1992; De Lange et al., 1994; Thomson et al., 1995]. However, barite may dissolve under sulphate-reducing conditions if the pore water becomes $\mathrm{SO}_{4}{ }^{2-}$ depleted [e.g., Brumsack and Gieskes, 1983; Van Os et al., 1991; Gingele and Dahmke, 1994]. In that case, dissolved $\mathrm{Ba}$ diffuses away and reprecipitates on encountering pore waters with sufficiently high sulphate concentrations. In sediments, this remobilization and subsequent precipitation is reflected by the presence of additional, mostly sharp Ba peaks [e.g., Van Os et al., 1991]. The profile of Si2 (Figure 3) does not contain any indication of extensive remobilization of $\mathrm{Ba}$. Because oxidation of organic matter does not influence the barite content of the sediment, the $\mathrm{Ba}$ profile reflects the initial organic carbon profile. The expected Ba-organic carbon relationship was used by
Van Santvoort et al. [1996] to reconstruct the initial organic carbon profile for the oxidized part of the sapropel in the three box cores (Figure 3 ).

The high S-concentrations in sapropels can be explained by two mechanisms. First, organic-rich sediments contain more pore water and therefore more pore water sulphate. Second, owing to the anoxic conditions in the sapropel during and after deposition, the available sulphate is used in the degradation of organic material. In reaction with Fe-oxyhydroxides or, more likely, dissolved $\mathrm{Fe}^{2+}$, the reduced S-species can form Fe-sulphides. When anoxia prevail long enough, more reduced S-species are produced than can be removed by the reactive $\mathrm{Fe}$. In that case a downward diffusion of reduced S-species is observed, and precipitation of Fe-sulphides below the sapropel takes place [Passier et al, 1996]. This leads to an S profile that shows high concentrations not only in, but also below, the sapropel (Figure 3).

Reduction of Fe-oxyhydroxides in and below the sapropel, followed by diffusion and re-precipitation at the oxidation front, changes the magnetic signal of the sediments. The ARM and NRM intensities dominantly are controlled by the amount of magnetic minerals in the sediment and, in particular, by finegrained single domain magnetite. It is obvious that these signals decrease at levels where Fe-oxyhydroxides have been dissolved, while much higher values may be found at depths of (re)precipitation. Recent research [Roberts et al., 1996] revealed higher concentrations of magnetic minerals (probably a magnetic Fe-sulphide) in sapropels. It is yet unknown which mineral is formed when the sapropel is oxidized and how this mineral contributes to the magnetic values of the sediment. Paramagnetic and ferrimagnetic minerals contribute to $\chi_{\text {in }}$. Therefore the differences in $\chi_{\text {in }}$ are less distinct than for ARM and NRM. Oxidation of a sapropel may lead to high values for especially ARM in the interval that initially contained the sapropel and may therefore be a good indicator of missing sapropels.

In summary, the profiles in the interval of $\mathrm{Si} 2$ are "ideally" developed. This means that the oxidation process is taking place at this moment, resulting in the formation of trace metal peaks and in the removal of organic material and reduced $\mathrm{Fe}-$ compounds. The observations in this interval are not influenced or overprinted by other diagenetic processes, and therefore we will use these profiles as a reference in the next sections where we will discuss older intervals.

\section{Oxidation of an Older Sapropel, Si46}

After the oxygen supply to a sapropel is cut off, for example, by an increased organic carbon flux, nitrate and Fe- and Mnoxyhydroxides act as electron acceptors in the decomposition of organic matter. In addition, under more reducing conditions, pore water sulphate is reduced, which may lead to dissolution of barite, i.e., to mobilization of $\mathrm{Ba}$. As a consequence of these postoxic and anoxic early diagenetic processes, the profiles of redox-sensitive elements may change significantly (Figure 4).

The Ba profile of sapropel si46 is similar to that around Si2: The curve has a semi-Gaussian shape. Using the same Ba-organic carbon relationship as in the calculations for the upper sapropel [Van Santvoort et al., 1996], the initial organic carbon profile is calculated. Part of Si46 must have been oxidized in a way similar to that for $\mathrm{Si} 2$, namely, the interval from 2174 to $2177 \mathrm{~cm}$ (the 


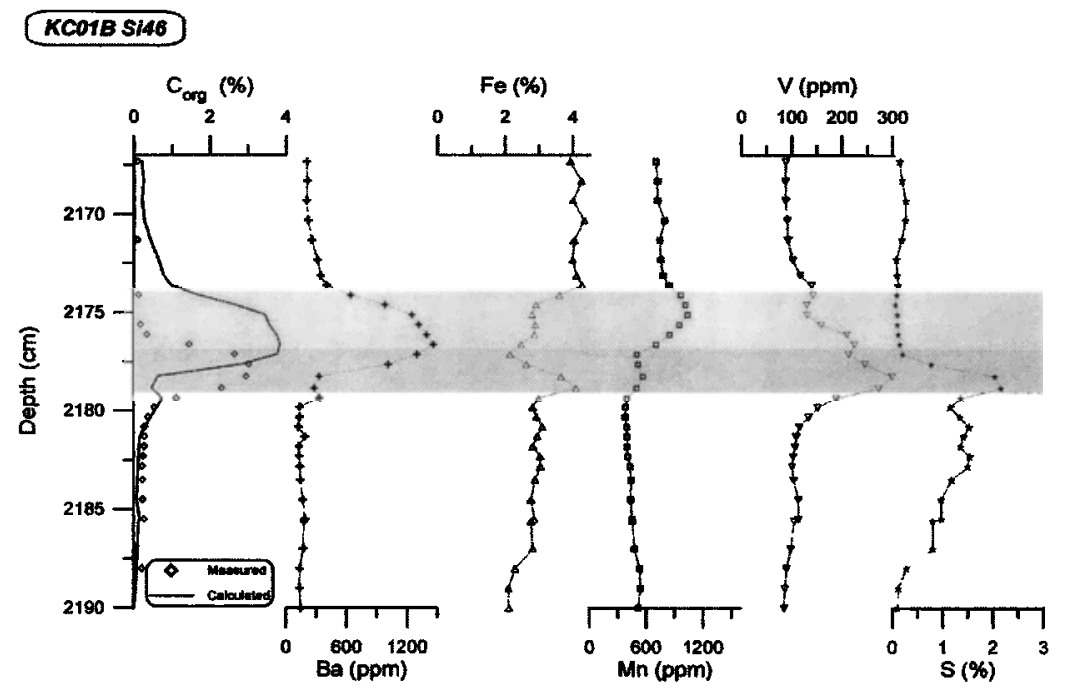

Figure 4. Concentration versus depth profiles of measured (diamonds) and calculated (solid line) organic carbon, $\mathrm{Ba}, \mathrm{Fe}, \mathrm{Mn}, \mathrm{V}$, and $\mathrm{S}$ for $\mathrm{Si} 46$ from core $\mathrm{KC01B}$. Concentration normalization and shadings are similar to those for Figure 3.

light shaded area in Figure 4): In this interval, high $\mathrm{Ba}$ concentrations are found, indicating that the initial organic carbon content of the sediment must have been higher. Furthermore, in the lowermost part of the profile, the measured organic carbon concentrations increase a few centimeters below the level where the initial concentrations (calculated from $\mathrm{Ba}$ ) start to increase. This points to mobilization of $\mathrm{Ba}$ in the lowermost part of the sapropel. The strong sulphate-reducing conditions that at some time must have occurred in the lower part of the sapropel are reflected by the high sulphide (up to $2.5 \%$ ) contents in that interval (Fig 4).

The downward movement of the oxidation front causes the formation of $\mathrm{Fe}$ - and $\mathrm{Mn}$-layers with maxima just below and just above the visible sapropel top, respectively. Near the base of $\mathrm{Si} 46$, the Fe-profile in Figure $\mathbf{4}$ has a maximum that is thought to consist of reduced $\mathrm{Fe}$-minerals like pyrite and $\mathrm{Fe}$-monosulphides. The oxidation front has caused the removal of these minerals in the oxidized upper part of the sapropel, as reflected by the $S$ profile (Figure 4). In $\mathrm{Si2}$, solid phase Fe-concentrations are enhanced in the oxidized part of the sapropel and reach a maximum at the oxidation front near the present top of the sapropel (Figure 3). In the same interval in Si46, Fe has been removed. A similar shift in depth is observed in the Mn profile: A maximum is expected just above the visible sapropel top (oxidation front), but for Si46, the highest Mn values are found 4 $\mathrm{cm}$ above the expected depth. A decrease in the oxygen flux to the sediment (for example, caused by an increased organic carbon flux) may cause an upward movement of the oxidation front. The sediments that contain the recently precipitated $\mathrm{Fe}$ - and $\mathrm{Mn}$ oxyhydroxides become postoxic again, which results in reduction of the oxyhydroxides. The oxygen supply may also be stopped by a new period of (near) anoxia of the bottom water (or by the earlier mentioned fluffy layer), with similar results. The only difference may be that in case of a complete oxygen cutoff, the dissolved species can diffuse over larger distances.

The trace metals that are closely correlated to the Fe content of the sediment, like $\mathrm{Zn}$ and $\mathrm{Ni}$ (not shown), have similar profiles as
Fe (Figure 4). The profile of $\mathrm{V}$, which should contain high concentrations at the oxic-postoxic interface (oxidation front) and in the sapropel, demonstrates the expected enrichments (Figure 4). The paleomagnetic parameters show the expected signals: Low values of NRM, ARM, and $\chi_{\text {in }}$ are recorded below the sapropel where Fe-oxyhydroxides are nearly completely used during oxidation of organic matter, and higher concentrations of magnetic minerals occur above the sapropel where Fe-bearing minerals have precipitated (Figure 2). Sampling at $10-\mathrm{cm}$ intervals was too coarse to observe the detailed effects of remobilization processes on the magnetic variables. Note that NRM data are not shown in this paper because they are identical to the ARM profile, with the difference that the NRM peaks are less distinct.

In summary, we can state that some of the initial geochemical and magnetic signals within sapropels may change or even disappear on postdepositional oxidation and subsequent postoxic conditions. The combination and sequence of geochemical and magnetic signals, however, may give an indication of the partial, or even complete, oxidation of a sapropel.

\section{"Missing" Sapropels}

The main criterion for sampling certain potential sapropel intervals at high resolution was the presence of high $\mathrm{Ba}$ concentrations in the $10-\mathrm{cm}$-resolution samples coinciding with a low organic carbon content and a peak in the insolation target curve (Figure 2). The organic carbon contents of samples from 11 selected intervals were all $<0.2 \%$.

To test whether the high $\mathrm{Ba}$ concentrations in the intervals with no visual signs of sapropel are in the form of barite (the principal form of $\mathrm{Ba}$ in visible sapropels) or sorbed onto oxyhydroxides and/or carbonates (and therefore of diagenetic origin), samples were treated with a reductive acid [Chester and Hughes, 1967]. In all samples, less than $2 \%$ of the $\mathrm{Ba}$ was removed in this way, and in most cases, less than $1 \%$ was removed. We therefore conclude that the $\mathrm{Ba}$ found in these 
intervals is mainly present in the form of barite and is likely to be of the same origin as the $\mathrm{Ba}$ enrichments found in visible sapropels (i.e., increased surface-water productivity). We also conclude on the basis of this evidence that these zones of $\mathrm{Ba}$ enrichment represent missing sapropels.

On the basis of results from these high-resolution samples, the 11 intervals can be ranked in three groups: (1) missing sapropels, (2) partially overprinted missing sapropels, and (3) completely overprinted missing sapropels.
Missing sapropels (si26, si30, si90, and si102). The first group of intervals that contains inferred missing sapropels is characterized by a quasi-Gaussian shaped Ba profile (Figure 5). The profiles do not contain evidence of $\mathrm{Ba}$ remobilization, except for a minor peak that lies above the main peak in si90, which means that the redox conditions never became extremely sulphate-reducing. Therefore the Ba profiles are thought to reflect the initial $\mathrm{Ba}$ concentrations, and these data can be used to calculate the initial organic carbon profile from the Ba-organic
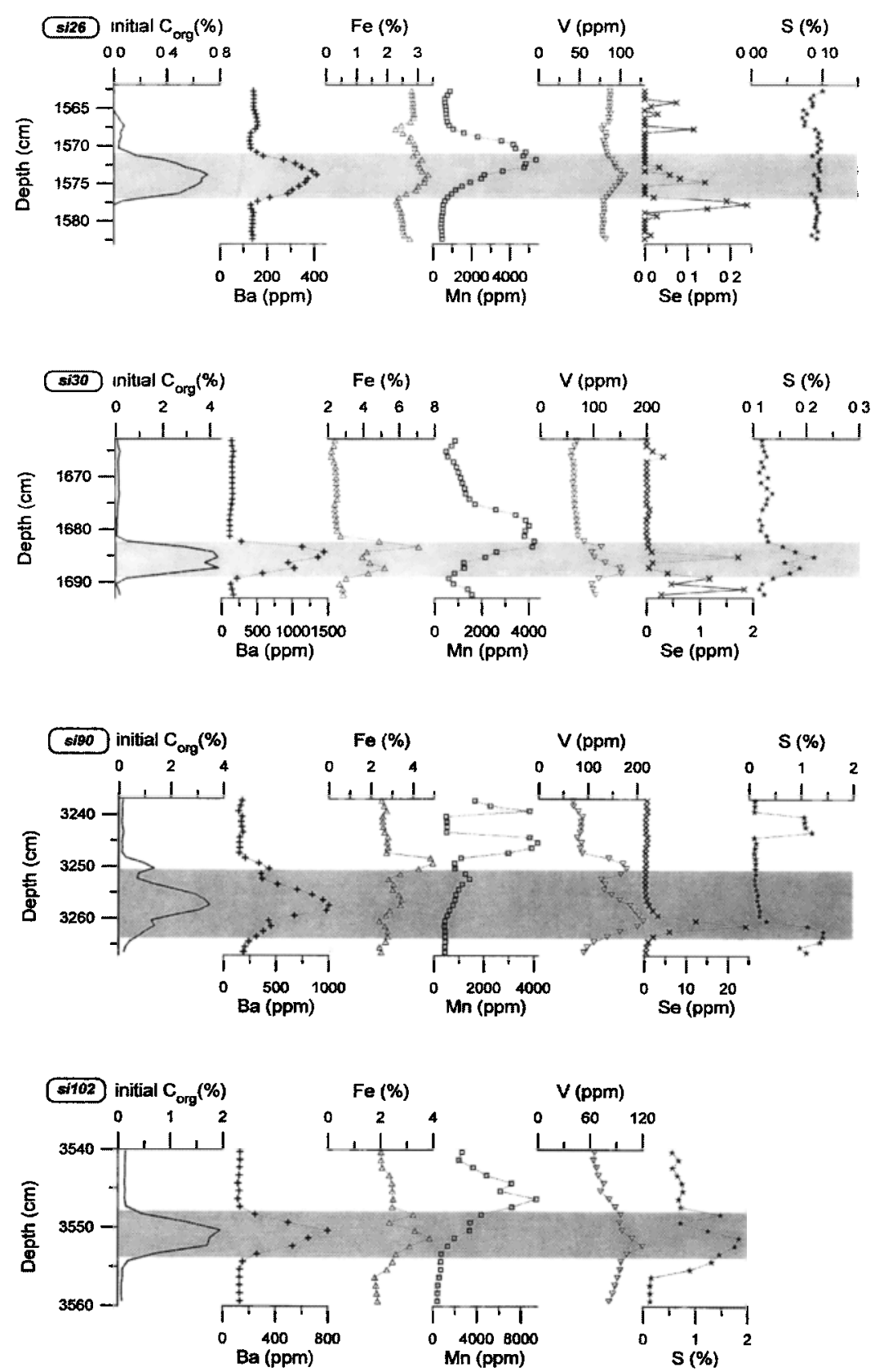

Figure 5. Concentration versus depth profiles of calculated initial organic carbon, Ba, Fe, Mn, V, Se, and S for si26, si30, si90, and si102 from core KC01B. Concentrations are normalized in the same way as for Figure 3 . The initial sapropel, obtained from the calculated organic carbon values, is indicated by the shaded area. No Se was analyzed in si102. 
carbon relationship that is observed in the UM box cores [Van Santvoort et al., 1996] (Figure 5). The four calculated organic carbon profiles differ considerably from each other: Maxima range from $0.8 \%$ in si26 to $4.3 \%$ in si30. According to the definition of Kidd et al. [1978], a sapropel must at least contain $2 \%$ organic carbon which would mean that si 26 would not have been classified as a sapropel. In this paper, however, we will use the term "sapropel" for a distinct sediment layer, which has an organic carbon content that is significantly higher than that of the surrounding hemipelagic sediment, and which is deposited in an open marine environment and is correlated with an insolation maximum. By comparing these data with those from sapropels that are visible today (Table 1), it appears that thickness and calculated maximum organic carbon concentrations are similar for visible sapropels and those inferred for the missing sapropels.

Iron- and Mn-rich layers are alternative indicators for the possible paleo-occurrence of a sapropel. Manganese peaks are located above the Fe peaks in all intervals. For a completely oxidized sapropel, it is expected that both peaks would be found near the base of the former sapropel. The downward movement of the oxidation front is determined by the amount of reduced species that can be oxidized and by the oxygen flux. As soon as the oxidation front reaches sediment with low organic carbon concentrations, the front will move down faster, resulting in lower solid phase concentrations of $\mathrm{Fe}$ and $\mathrm{Mn}$. It is clear that the maxima are located well above the inferred base of the sapropels, similar to the Fe and Mn peaks in Si46. The Mn peak is always located close to the inferred top of the initial sapropel and may therefore reflect, similar to $\mathrm{Si} 2$, the end of sapropel formation.
Ongoing diagenesis, after oxidation of the sapropel, is clearly evident in si30 by the double Fe-peak. In the missing sapropel interval, $\mathrm{Mn}$ in si30 is partly incorporated in or adsorbed onto carbonates, which results in a good correlation between $\mathrm{Ca}$ and $\mathrm{Mn}$. Under postoxic to anoxic conditions, the maximum dissolved Mn concentration in pore water is typically limited by the precipitation of Mn carbonate [e.g., Suess, 1979; De Lange, 1986]. Overgrowth of Mn-carbonates on foraminifera tests was reported by Boyle [1983] who stated that these coatings can account for a significant proportion of the $\mathrm{Mn}$ in reduced (deepsea) sediments. Reaction of dissolved $\mathrm{Fe}$ with $\mathrm{Mn}$-oxyhydroxides results in dissolved $\mathrm{Mn}$ and solid-phase Fe-oxyhydroxides. A considerable amount of the Mn-oxyhydroxides can thus be reduced, and $\mathrm{Mn}^{2+}$ may subsequently have diffused to other levels or be incorporated into carbonates.

Sulphur contents are low in the oxidized intervals, except for si102 and the lower part of si90 where total-S concentrations of up to $2 \%$ are found (Figure 5). The peak around si102 is thought to originate from sapropel Sil00, according to the sulphidise down mechanism described by Passier et al. [1996]. The S peak in si90, at the base of the initial sapropel, may indicate the last remnant of this sapropel. The origin of the peak above si90 is yet unknown.

Ongoing diagenesis is also responsible for the different profiles of redox-sensitive elements such as Se and V. In si30 and si90, peaks of both elements are found near the base of the missing sapropel (Figure 5), indicating that this was the depth of the ancient oxidation front and that oxygen did not diffuse deeper than this level. For si26, the Se concentrations are very low and

Table 1. Measured and Calculated Parameters for the Different ("Missing") Sapropels

\begin{tabular}{|c|c|c|c|c|}
\hline & $\begin{array}{c}\text { Maximum } \mathrm{C}_{\text {org }} \\
\text { Concentration Measured, \% }\end{array}$ & $\begin{array}{l}\text { Maximum } \mathrm{C}_{\text {org }} \\
\text { Concentration } \\
\text { Calculated, }{ }^{2} \%\end{array}$ & Thickness, ${ }^{b} \mathrm{~cm}$ & Total $\mathrm{C}_{\text {org }},{ }^{\mathrm{c}} 10^{-2} \mathrm{~mol} \mathrm{~cm}^{-2}$ \\
\hline UM15 S12 & 37 & 3.8 & $? ?$ & $? ?$ \\
\hline UM26 S12 & 30 & 3.2 & 120 & 210 \\
\hline UM35 Si2 & 2.8 & 36 & 135 & 210 \\
\hline Silo (S4) & 27 & 49 & 155 & 196 \\
\hline Sil2 (S5) & 34 & 6.3 & 7.0 & 1.91 \\
\hline Sil 8 (S7) & 59 & 49 & 101 & 045 \\
\hline S122 (S9) & 20 & 43 & 7.3 & 097 \\
\hline S146 (S12) & 30 & 88 & 8 & 408 \\
\hline$S_{192}$ & 23 & 41 & 68 & 059 \\
\hline s18 & missing sapropel & 09 & $? ?$ & 135 \\
\hline s114 & missing sapropel & 1.0 & $? ?$ & 0.86 \\
\hline s126 & missing sapropel & 0.7 & 50 & 012 \\
\hline si30 & missing sapropel & 4.4 & 70 & 133 \\
\hline s1 40 & missıng sapropel & 16 & 79 & 073 \\
\hline \multirow[t]{2}{*}{ s158 } & missing sapropel & 25 & $7 ?$ & 123 \\
\hline & missing sapropel & 22 & 79 & 129 \\
\hline si60 & missing sapropel & 06 & 39 & 028 \\
\hline s186 & missing sapropel & 08 & $? ?$ & 072 \\
\hline s190 & missing sapropel & 3.5 & 16.0 & 149 \\
\hline si98 & missing sapropel & 28 & $? ?$ & 067 \\
\hline s1 102 & missing sapropel & 2.0 & 5.0 & 0.42 \\
\hline
\end{tabular}

a Organic carbon is calculated using the equation derived from the $\mathrm{Ba}-\mathrm{C}_{\mathrm{org}}$ relationship derived from the UM-box cores [Van Santvoort et $a l, 1996]$

${ }^{b}$ Thickness is the interval with calculated organic carbon values above $0.3 \%$

${ }^{c}$ Total $C_{\text {org }}$ is calculated over the interval with values above $03 \%$, using a dry sediment content of $075 \mathrm{~g} \mathrm{~cm}^{-3}$, corresponding to a water content of $\sim 70 \%$ of the sediment. Note that UM15 does not contain a complete sapropel interval, and therefore no thickness and total organic carbon value can be calculated. 
therefore highly unreliable. However, the main (lowermost) peak does not coincide with a $\mathrm{V}$ peak. Consequently, it is likely that the oxidation front moved deeper into the sediment, below the sampled interval. The relatively low concentration of organic carbon in the missing si26 sapropel (Table 1) indicates that this sapropel has been easy to oxidize.

In the four missing sapropels of this group, the ARM, NRM, and $\chi_{\text {In }}$ values are similarly low undemeath the inferred sapropel base and are high in and above the former sapropel (Figure 2). The magnetic signals, as observed in these intervals, are similar to those observed near sapropels that are visible today (compare Figure 2).

On the basis of geochemical and magnetic data, we conclude that the intervals around si26, si30, si90, and si102 initially contained sapropels that have subsequently been completely oxidized. Ongoing diagenesis has altered the distribution of redox-sensitive elements considerably. In two intervals, si30 and si90, Se peaks indicate the position of the ancient oxidation front. Redox conditions never became extremely anoxic because the $\mathrm{Ba}$ profiles contain only minor traces of remobilization.

Partially overprinted missing sapropels (si58, si60, si86, and si98). Partially overprinted missing sapropels all have $\mathrm{Ba}$ profiles that contain multiple peaks: two in si60, si86 and si98, and four in si58 (Figure 6). Mobilization of Ba probably occurred in these intervals due to dissolution of barite under sulphatereducing conditions. Such mobilization prohibits the calculation of the initial organic carbon profile since it is unknown to which extent the initial Ba concentrations changed at each depth level. It is also impossible to deduce the exact thickness of the initial sapropel from these profiles because it is likely that the $\mathrm{Ba}$ is distributed over a wider interval now than it has been during formation of the sapropel. However, the distance over which dissolved $\mathrm{Ba}$ may have diffused is likely to be small, because sulphate-reducing conditions were probably present only in a restricted part of the sediment column. During sapropel formation, there is a continuous supply of bottom water sulphate to the pore water, as demonstrated by Passier et al. [1996]. In such situations, $\mathrm{Ba}$ cannot diffuse over large distances but will reprecipitate as barite on encountering pore water with sufficient sulphate. Ongoing sulphate reduction after deposition of the sapropel is also unlikely. In almost all sapropels that are still visible now, including the $\mathrm{Si} 2$, active sulphate reduction is absent [e.g., Pruysers et al., 1993).

Missing sapropel si58 is a special case which contains a quadruple Ba peak which can have three possible origins. (1) The $\mathrm{Ba}$ profile represents the initial $\mathrm{Ba}$ signal: Four separate periods of sapropel formation must have occurred. Noncontinuous sapropel formation (e.g., Si16 or S6) may be caused by short periods of bottom water renewal or by decreases in primary production. (2) The $\mathrm{Ba}$ profile is the result of mobilization and reprecipitation of barite at different levels. (3) The Ba profile is the result of two missing sapropels, each having an initial peak and a mobilization peak. The peaks at 2505 and $2525 \mathrm{~cm}$ would then be the initial Ba peaks, since they still show a gradual increase and decrease at the base and top of the missing sapropel. The peaks at 2495 and $2515 \mathrm{~cm}$, however, have a relatively sharp transition from high to low Ba concentrations in the upper part of the peak, which may be an indication of diagenetic formation (compare the upper peak in si86; Figure 6). This is our preferred interpretation, because it is easier to completely oxidize two thin sapropels than to oxidize a single thick sapropel (as required by option 1) and it does not need special diagenetic conditions as required by option 2 .

Assuming that the amount of $\mathrm{Ba}$ above background concentrations is representative for the total amount of $\mathrm{Ba}$ that has been deposited initially during sapropel formation, it is possible to calculate the total amount of initial organic carbon (Table 1). Calculated values are of the same magnitude as those of nonoverprinted missing sapropels and as sapropels that are still visible in the present-day sediment column.

The sulphur concentrations in the oxidized intervals are low (Figure 6) and indicate no other sulphur source than pore water sulphate. All reduced sulphur minerals have been oxidized by the oxidation front.

The profiles of solid phase $\mathrm{Fe}$ and $\mathrm{Mn}$ are more complex than in the nonoverprinted missing sapropels: The $\mathrm{Fe}$ profiles are different, with only minor peaks. Owing to the more reducing conditions, more $\mathrm{Fe}$ has been remobilized and has diffused outside the sampled intervals. This remobilization is reflected by the relatively constant values of the paleomagnetic parameters, ARM, NRM, and $\chi_{\text {in }}$ (Figure 2). The Mn concentrations are relatively high in the interval with high $\mathrm{Ca}$ values (not shown) and are thought to be associated with carbonates.

In all intervals (except si58) a clear $\mathrm{V}$ peak is visible. The position of the peak is mostly in the interval which we interpret to represent remobilized $\mathrm{Ba}$. In case of a completely oxidized sapropel this peak was expected to appear at the base of the Baenrichment. It seems therefore that the present-day $\mathrm{V}$ peak no longer indicates the depth of the ancient oxidation front.

In conclusion, these intervals contain missing sapropels, though the evidence is less clear than for the nonoverprinted missing sapropels. The combination of the observed $\mathrm{Ba}$ profile with remobilization peaks and the peaks in redox-sensitive elements in, or close to, these intervals point to a former sapropel that has been completely oxidized. The total $\mathrm{Ba}$ may still represent the total organic carbon flux but does not necessarily indicate the precise sapropel boundaries.

Overprinted missing sapropels (si8, si14, and si40). Overprinted missing sapropels are characterized by $\mathrm{Ba}$ profiles that indicate severe mobilization of $\mathrm{Ba}$ (Figure 7). All profiles contain higher than background ( $>200 \mathrm{ppm}$ ) Ba values over a wide depth interval, often with several minor $\mathrm{Ba}$ peaks. The quasi-Gaussian shaped Ba peak observed in si40 is located on top of a relatively high $\mathrm{Ba}$ background and is therefore probably not representative of the original profile. In these intervals, severe sulphate reduction is inferred to have taken place where the reduction rate was (much) faster than the diffusion rate of sulphate from the bottom water. As a result, pore water sulphate concentrations decreased to a level that barite was dissolved. Similar to the profiles of the partially overprinted missing sapropels, these profiles cannot be used to calculate the initial organic carbon profile, nor can the initial sapropel boundaries be indicated.

The reduced sulphur minerals that formed during sapropel formation have all been subsequently oxidized. Pore water sulphate makes up the present $\mathrm{S}$ concentrations.

The sharp Ba peak at $683 \mathrm{~cm}$ in si8 is not of diagenetic origin. A peak at this depth is also found in the profiles of $\mathrm{Al}, \mathrm{Ce}, \mathrm{Co}$, $\mathrm{Fe}, \mathrm{Na}, \mathrm{P}, \mathrm{S}$, and $\mathrm{Ti}$. At the same level, $\mathrm{Be}, \mathrm{Cr}, \mathrm{K}, \mathrm{Li}, \mathrm{Mg}, \mathrm{Sc}$, and $\mathrm{V}$ show (strong) negative peaks. Note that not all elements are 

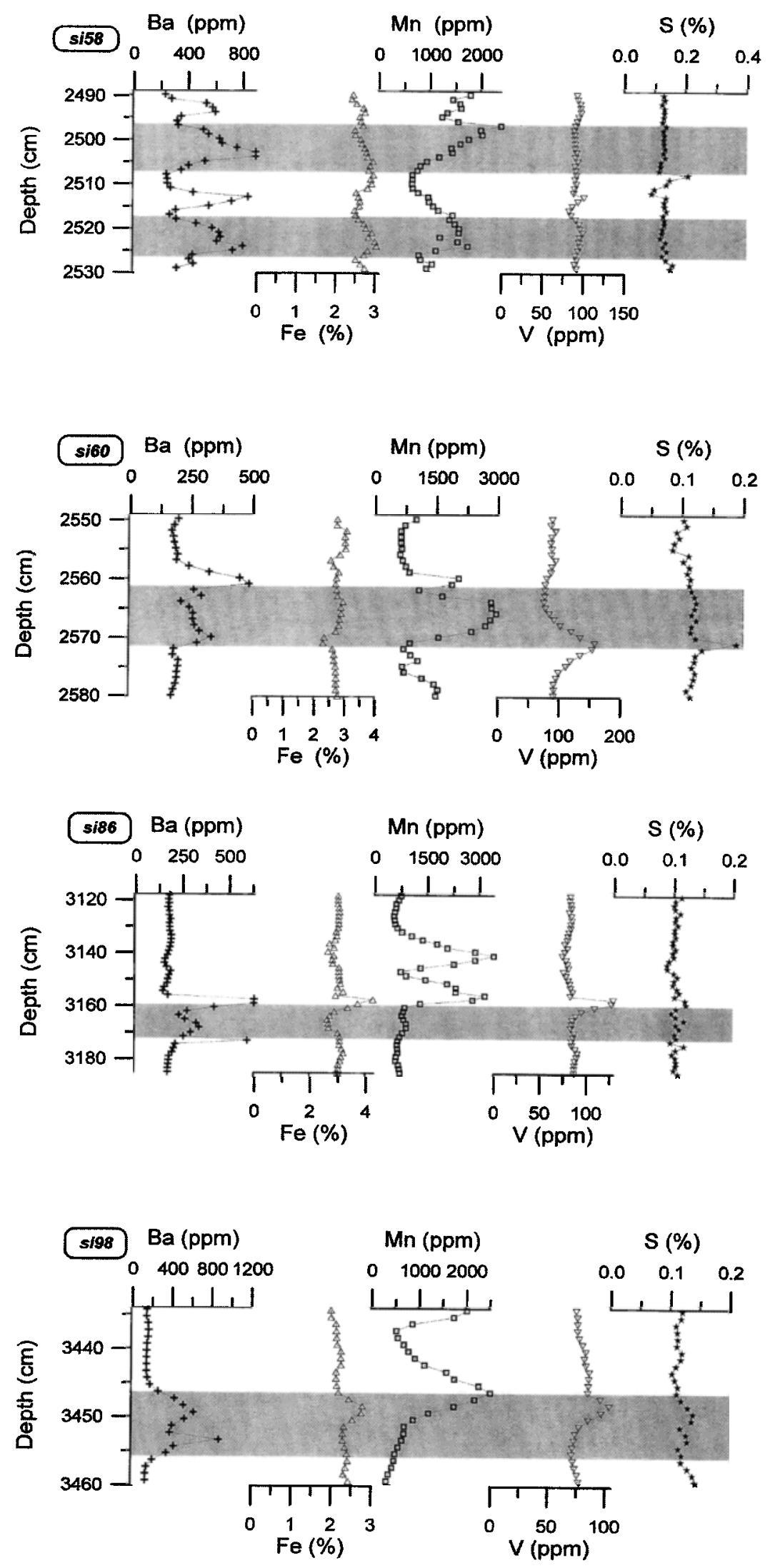

Figure 6. Concentration versus depth profiles of $\mathrm{Ba}, \mathrm{Fe}, \mathrm{Mn}, \mathrm{V}$, and $\mathrm{S}$ for si58, si60, si86, and si98 from core KC01B. Concentrations are normalized in the same way as for Figure 3; the initial sapropel is indicated by the shaded area. 

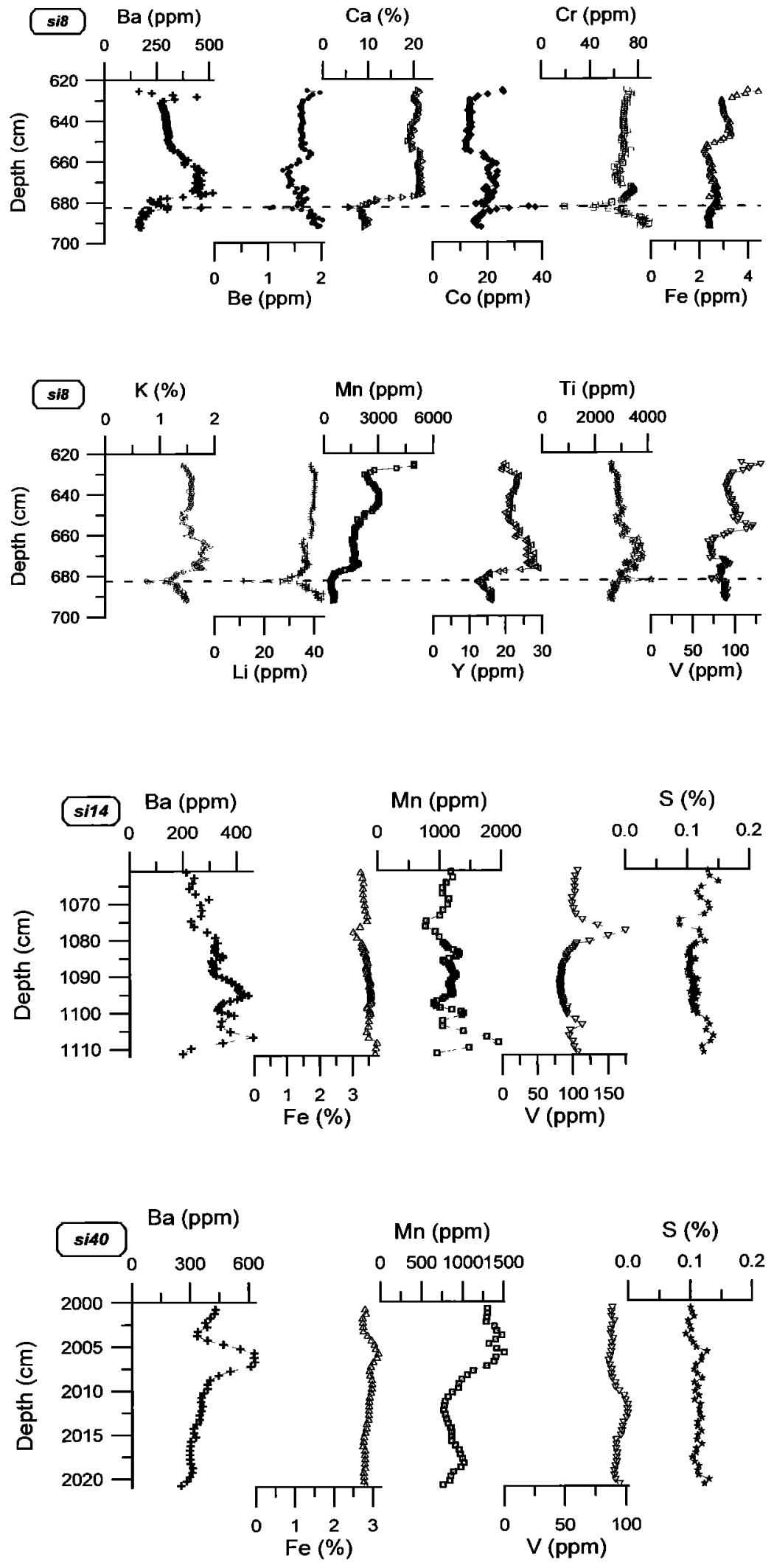

Figure 7. Concentration versus depth profile of $\mathrm{Ba}, \mathrm{Be}, \mathrm{Ca}, \mathrm{Co}, \mathrm{Cr}, \mathrm{Fe}, \mathrm{K}, \mathrm{Li}, \mathrm{Mn}, \mathrm{Y}$, Ti, and $\mathrm{V}$ for si8 and $\mathrm{Ba}, \mathrm{Fe}$, $\mathrm{Mn}, \mathrm{V}$, and S for si14 and si40 from core KC01B. All elements, except Ca and S, are normalized to $\mathrm{Al}$ and multiplied by the average $\mathrm{Al}$ content to minimize the dilution effect by $\mathrm{CaCO}_{3}$. The dashed line in the si8 profiles indicates the position of the tephra layer. 
shown in Figure 7. Simultaneously, the Ca concentration drops to values below $6 \%$, which is extremely low for eastern Mediterranean sediments. The suite of elemental concentrations at this level points to a volcanic origin. The age of the sediment is $79 \mathrm{kyr}$, as calculated by Langereis et al. [1997], which is similar to the age of about $82 \mathrm{kyr}$ of tephra layer X-2 [Cita et al., 1977]. For the top few meters of this core, the dating methods of Langereis et al. [1997] and Cita et al. [1977] give similar ages: For Si12 (sapropel S5), ages of 124 and 125 kyr respectively are obtained. Therefore it is likely that this layer represents tephra layer X-2. This tephra layer contains sanidine, augite, biotite, occasional plagioclase, hornblende (uncommon), apatite, and sphene [Vezzoli, 1991] and is completely different to the surrounding sediments, which results in sharp (negative) peaks. The tephra is fine-grained and has a color similar to that of the surrounding sediment. Therefore this layer was not previously identified. X-ray diffraction (XRD) analyses of the two samples that were taken in this layer confirm that it is of volcanic origin. Both samples contain considerable amounts of anorthite $(>25 \%)$ and smaller amounts of albite, augite, phlogopite, and kaolinite. Consequently, the high $\mathrm{Ba}$ in this interval is not sapropel-related.

When focusing on the interval above this tephra layer and the intervals around sil4 and si40, no distinct $\mathrm{Fe}$ and $\mathrm{Mn}$ peaks are found. On the basis of the $\mathrm{Ba}$ profiles, we conclude that redox conditions must have been more anoxic for these intervals than for the previously discussed intervals. Most Fe- and Mnoxyhydroxides have probably been reduced and have diffused away from this interval. In addition, no clear spikes that point to missing sapropels have been found from other redox-sensitive elements. Because Fe-oxyhydroxides have been mobilized, no clear signals are observed in the paleomagnetic variables; only relatively constant values remain (Figure 2 ).

In conclusion, these intervals may contain a missing sapropel, but the evidence for this (i.e., occurrence of a Ba enrichment at an insolation maximum) is ambiguous. The deposition of subsequent sapropels near these intervals may be responsible for the extensive diagenetic changes observed around si 14 and si40. The cause of the extensive remobilization in si8 is less clear. Sapropel Sil0 (S4) is found below this interval, but it is unlikely that this layer, which does not show any evidence of sulphate reduction, could have been directly responsible for the complete removal of most traces of a missing sapropel in si8.

\section{Insolation Maxima Without a Corresponding Ba Peak}

Not all distinct maxima in the insolation target curve have a corresponding Ba peak (Figure 2). This may be related to four possible reasons. The first of these is the initial sampling resolution of $10 \mathrm{~cm}$ was too coarse to reveal all $\mathrm{Ba}$ enrichments.

Second, if sapropels do not form at every insolation maximum, there may never have been a Ba-enrichment at that level. This could indicate that climate changes, which lead to higher paleoproductivity and subsequent sapropel formation, do not always occur or that they occur at an intensity that is too low to initiate higher productivities. There is no straightforward relationship between the relative value of the insolation maximum and the height of the Ba peak (Figure 2). With the present state of knowledge of sapropel formation, and its expression in sediments, it is not possible to decide if sapropel formation has occurred at every insolation maximum. We have shown that initially more sapropels have been deposited than are presently observed and have supplied potential tools to detect such initial presence.

The third reason is although the sapropels that are preserved in sediments up to $1 \mathrm{Ma}$ always have elevated $\mathrm{Ba}$ concentrations, sapropel formation may have occurred without a change in the $\mathrm{Ba}$ content of the sediment. This is only possible if the higher organic carbon concentrations in sapropels result strictly from enhanced preservation due to anoxic bottom water conditions. This option does not seem to be realistic, however, because no sapropel that is found at present is of this type. Sapropels that formed by enhanced preservation may only have a relatively low organic carbon concentration, which would easily result in their rapid oxidation. Consequently, such hypothetical sapropels would no longer be visible.

The fourth is that oxidation of sapropels leads to diagenetic signals in the sediment. If a new, larger sapropel is deposited above an oxidized sapropel, however, the diagenetic processes in the new sapropel can (partially) overprint older ones, as was demonstrated above. Further diagenesis cannot only remobilize the metal-rich layers, but it may also dissolve the Ba peaks which subsequently precipitate at a different level or become part of the new diagenetic signal. This means that (almost) no signs of the older sapropel are left in the sediment and that a missing sapropel is no longer chemically detectable at that level.

With respect to these complicating factors, it is difficult to demonstrate that a sapropel was originally deposited at every insolation maximum. Furthermore, it is unknown to what extent and by what mechanism(s) the climate changes and how this corresponds to sapropel formation. It is unlikely that the present combination of geochemical and paleomagnetic data alone can solve this problem. However, we have clearly demonstrated that there were initially more sapropels than those observed today in the sediments of the last 1.1 Myr in the eastern Mediterranean Sea. This is an important finding for the study and interpretation of sedimentary paleoclimatic signals found in this area. Furthermore, inorganic geochemical and, to a lesser extent, magnetic signals can be used to reveal major changes in paleoclimatology and paleoceanography. In this way, a large number of samples can easily be processed, allowing for a much more detailed data set.

\section{Conclusions}

Sapropels always display high $\mathrm{Ba}$ concentrations, and they always appear at maxima in the insolation target curve. After oxidation of a sapropel, the $\mathrm{Ba}$ profile is preserved. Barium, present as barite, may only be mobilized under strongly sulphate reducing conditions. Early diagenesis produces a downward moving oxidation front, which causes the formation of $\mathrm{Fe}-$ and Mn-rich layers of characteristic shape, as well as typical distributions of other redox-sensitive elements. In the 1.1-Ma sediment column of core $\mathrm{KCO} 1 \mathrm{~B}$, a large number of Ba spikes have been found that are not related to visible sapropels. Most of these $\mathrm{Ba}$ peaks lie near maxima in the insolation target curve, which suggested the former presence of additional, now "missing" sapropels.

Four of the sampled intervals (si26, si30, si90, and si102) contain chemical signals that indicate the complete oxidation of sapropels. The distribution of $\mathrm{Ba}$ and (trace) elements is similar to that observed in a partly oxidized sapropel (Si46). The 
magnetic properties of missing sapropels show a pattern similar to that of visible sapropels, which supports the conclusion that these intervals are the remnants of completely oxidized sapropels.

In four other intervals (si58, si60, si86, and si98), ongoing diagenesis has partially overprinted the signals that formed during oxidation of the sapropel. However, the combination of elevated $\mathrm{Ba}$ concentrations and peaks in the redox-sensitive elements are useful indicators for missing sapropels. The profiles of si8, si14, and si40 are more strongly overprinted and contain only faint traces of missing sapropels.

There is no direct relation between the relative value of the insolation maximum and the height of the Ba peak found at that level: Visible sapropels, which have high $\mathrm{Ba}$ concentrations, are not always found at the most pronounced insolation maxima. Furthermore, $\mathrm{Ba}$ peaks are not observed at each insolation maximum. This may be caused by (1) the sampling resolution which was too coarse to recover all $\mathrm{Ba}$ enrichments; (2) sapropel formation by enhanced preservation rather than by increased primary production; (3) overprinting by more recent diagenesis and (4) the absence of sapropel formation.
We have demonstrated that the 1.1-Ma sediment record of core $\mathrm{KC} 01 \mathrm{~B}$ initially contained more sapropels than are visible today. Geochemical and magnetic parameters are useful tools to reveal the occurrence of these missing sapropels and therefore major changes in paleoclimate and paleoceanography, even though observations may be complicated by postoxidative diagenetic alterations of the sediment.

Acknowledgments. We thank the crews and scientific parties of the Marion Dufresne 1991 and Urania 1994 cruises H de Waard, E Konmin, $M$ Kleın-Tank, $D$ van der Meent, $R$ Alink, and $P$ Anten ase acknowledged for their assistance with geochemical analyses. Paleomagnetıc and rock magnetic measurements were carried out by $\mathrm{J}$. Meıjer and P-J. Verplak. M.B. Cita and staff and students are acknowledged for the laborious picking of the microfossils for stable isotope analysis. We thank C.H. van der Weijden for critically reading the manuscript. Reviews by R. Zahn, A. Roberts and one anonymous reviewer and editorial work by M.L. Delaney greatly improved the original version This work was supported by the European Union Marıne Science and Technology program, contract numbers $900022 \mathrm{C}$ (MARFLUX) and MAS2-CT93-0051 (PALAEOFLUX) MJD. acknowledges support of the Royal Netherlands Academy of Sciences and Arts in the form of a fellowship. This is NSG paper 96.1213.

\section{References}

Berger, A, and M.F Loutre, Astronomical solutions for paleoclimate studies over the last 3 million years, Earth Planet Sci. Lett., 111, 369-382, 1992.

Boyle, E A, Manganese carbonate overgrowths on foraminifera tests, Geochim Cosmochim Acta, $47,1815-1819,1983$

Brumsack, J.H. and J.M. Gieskes, Interstitual water trace element chemistry of laminated sediments from the Gulf of California, Mexico, Mar. Chem. 14, 89-106, 1983.

Calvert. S.E, Geochemistry of Pleistocene sapropels and associated sediments from the eastem Mediterranean, Oceanol. Acta, 6, 255267,1983

Calvert, S E., and M.R. Fontugne, Geochemistry and origin of Mediterranean sapropels, EOS Trans $A G U, 69,1234,1988$.

Calvert, S E, S. Muhkerjee, and R.J. Morris, Trace metals in fulvic and humic acids from modern organic-rich sediments, Oceanol Acta, 8, 167 . 173,1985

Chester, R., and M.J. Hughes, A chemical technique for the separation of ferromanganese minerals, carbonate minerals and adsorbed trace elements from pelagic sediments, Chem. Geol., 2, 249-262, 1967.

Cita, M.B , C. Vergnaud-Grazzin1, H Chamley, N. Ciaranfi, and $S$ D'Onofrio, Paleoclimatic record of a long deep sea core from the eastem Mediterranean, Quat Res., 8, 205-235, 1977

Dekkers, M J , C G Langereis, S.P Vriend, P.J M van Santvoort, and G.J. de Lange, Fuzzy cmeans cluster analysis of early diagenetic effects on natural remanent magnetisation acquisition in a $11 \mathrm{Myr}$ piston core from the central Mediterranean, Phys. Earth Planet. Inter , 85, 155-171, 1994

De Lange, G.J, Early diagenetic reactions in interbedded pelagic and turbiditic sediments in the Nares Abyssal Plain (western North Atlantic) Consequences for the composition of sediment and interstitial water, Geochım. Cosmochim. Acta, 50, 2543-2561, 1986

De Lange, G.J., J.J. Middelburg, and P.A. Pruysers, Discussion: Middle and Late Quaternary depositional sequences and cycles in the eastern Mediterranean, Sedimentology, $36,151-158,1989$
De Lange, G.J., B. van Os, P.A. Pruysers, J.J. Middelburg, D. Castradon, $P$ van Santvoort, P J Müller, H. Eggenkamp, and F.G. Prahl, Possible diagenetic alteration of palaeo proxies, in Carbon Cycling in the Glacial Ocean Constramts on the Ocean's Role in Global Change, edited by R. Zahn et al , NATO ASI Ser, $117,225-258,1994$

Dymond, J, E Suess, and M. Lyle, Barium in deep-sea sediment: A geochemical proxy for paltoproductivity, Paleoceanography, 7, 163181,1992

Emerson, S R, and S.S Huested, Ocean anoxia and the concentrations of molybdenum and vanadium in seawater, Mar. Chem., 34, 177 . 198,1991

Gingele, F., and A. Dahmke, Discrete barium particles and barium as tracers of paleoproductivity in South Atlantic sediments, Paleoceonagraphy, 9, 151-168, 1994.

Hem, J.D., C.J. Lind, and C.E. Roberson, Coprecipitation and redox reactions of manganese oxides with copper and nickel, Geochim Cosmochim. Acta, 53, 2811-2822, 1989

Higgs, N C , J Thomson, T R S Wilson, and I.W Croudace, Modification and complete removal of eastem Mediterranean sapropels by postdepositional oxidation, Geology, 22, 423426, 1994

Hilgen, F J , Astronomical calibration of Gauss to Matuyama sapropels in the Mediterranean and implication for the geomagnetic polarity time scale, Earth Planet Scr. Lett, 104, 226-244, 1991

Hilgen, F J., L.J Lourens, A Berger, and M.F Loutre, Evaluation of the astronomically calibrated timescale for the late Pliocene and earliest Pleistocene, Paleoceanography, 8 , 549-565, 1993

Hilgen, F J., W. Krijgsman, C.G. Langereis, L.J. Lourens, A Santarell, and W.J. Zachariasse, Extending the astronomical (polarity) time scale into the Miocene, Earth Planet. Scr. Lett., 136, 495-510, 1995.

Imbrie, J, and J Z. Imbrie, Modeling the climatic response to orbital variations, Science, 207 943-953, 1980

Kıdd, R.B., M.B. Cita, and W.B.F. Ryan,
Stratigraphy of eastern Mediterranean sapropel sequences recovered during DSDP Leg 42A and their paleoenvironmental significance, Inttsal Rep. Deep Sea Drill. Proj., 42A, 421443,1978

Klinkhammer, G., and C E Lambert, Preservation of organic matter during salunity excursions, Nature, 339, 271-274, 1989.

Krijgsman, W, F J. Hilgen, C G. Langeress, A. Santarell, and W.J. Zachariasse, Late Miocene magnetostratigraphy, biostratıgraphy and cyclostratigraphy from the Mediterranean Earth Planet. ScI. Lett. I36, 475-494, 1995.

Langere1s, C G., M J Dekkers, P.J.M van Santvoort, and G J.de Lange, Magnetostrat1graphy and astronomical calibration of the last $11 \mathrm{Myr}$ from a Eastern Mediterranean piston care and dating of short events in the Brunhes, Geophys. J. Int., 129. $75-94,1997$.

Laskar, J, The chaotic motion of the solar system. A numerical estimate of the size of the chaotic zones, Icarus, 88, 266-291, 1990.

Laskar, J., F Joutel, and F. Boudin, Orbital, precessional, and insolation quantities for the Earth from -20 to $+10 \mathrm{Myr}$, Astron. Astrophys., $270,522-533,1993$

Levi, S., and S.K. Banerjee, On the possibility of obtaining relatıve paleointensities from lake sediments, Earth Planet. Scl Lett, 29, 219. 226,1976

Lourens, L J, Astronomical forcing of Mediterranean climate during the last 5.3 million years, Ph.D thesis, $247 \mathrm{pp}$, Utrecht Univ, Utrecht, Netherlands, 1994

Lourens, L J., F.J. Hilgen, W J. Zacharıasse, A.A $M$ van Hoof, A. Antonarakou, and C. Vergnaud-Grazzini, Evaluation of the PlioPleistocene astronomical timescale, Paleoceanography, 11, 391-413, 1996

Mackensen, A, H-W Hubberten, T Bickert, G Fischer, and D.K Futterer, The $\delta^{13} \mathrm{C}$ in benthicforaminiferal tests of Fontbotia Wuellerstorfi (Schwager) relative to the $\delta^{13} \mathrm{C}$ of dissolved inorganic carbon in Southem Ocean deep water Implications for glacial ocean circulation models, Paleoceanography, 8, 587$610,1993$.

Passier, H F, J J Middelburg, B.J.H. van Os, and 
G.J. de Lange, Diagenetic pyritisation under eastern Mediterranean sapropels caused by downward sulphıde diffusion, Geochim. Cosmochmm. Acta, 60, 751-763, 1996.

Prell, W L., and JE Kutzbach, Monsoon variability over the past 150,000 years, $J$. Geophys. Res., 92, 8411-8425, 1987.

Pruysers, P A., G.J de Lange, and J J. Middelburg, Geochemistry of eastern Mediterranean sedıments Primary sediment composition and diagenetic alterations, Mar. Geol., I00, 137154, 1991

Pruysers, P.A , G J. de Lange, J.J. Middelburg and $D J$ Hydes, The diagenetic formation of metalrich layers in sapropel-containing sediments in the eastem Mediterranean, Geochım Cosmochim. Acta, 57, 527-536, 1993.

Roberts, A.P, J.S. Stoner and C Richter, CoringInduced magnetic overprints and limitations of the long-core paleomagnetic measurements technique Some observations from leg 160 , eastem Mediterranean Sea, Proc. Ocean Drill Program Inttal Rep., 160, 497-505, 1996.

Rossignol-Strick, M, African monsoons, an immediate clımatıc response to orbital insolation, Nature, 303, 46-49, 1983

Rossignol-Strick, M., Mediterranean Quaternary sapropels, and immediate response of the African monsoon to variations of insolation, Palaeogeogr Palaeoclimatol Palaeoecol, 49, 237-263, 1985

Ryan, W.B.F, Stratıgraphy of Late Quatemary sedıments in the eastern Mediterranean, in The Mediterranean Sea: A Natural Sedimentation Laboratory, edited by D.J. Stanley, pp. 146169, Van Nostrand Reinhold, New York, 1972

Suess, E., Mineral phases formed in anoxic sediments by microbial decomposition of organic matter, Geochm. Cosmochrm. Acta, 43, 339-352, 1979.

Sutherland HE SE Calvert, and R J Morrs, Geochemical studies of the Recent sapropel associated sediment from the Hellenic outer ridge, eastern Mediterranean Sea, I Mineralogy and chemical composition, Mar Geol., 56, 7992,1984

Ten Haven, H.L., J.W de Leeuw, P.A. Schenck, and GT. Klaver, Geochemistry of Mediterranean sedıments, Bromine/organic carbon and uranium/organic carbon ratios as indicators for different sources of input and post-depositional oxidation, respectively, Org Geochem , 13, 255-261, 1988

Thomson, J, NC Higgs, I W Croudace, S Colley, and D J Hydes, Redox zonation of elements at an oxic/post-oxic boundary in deep-sea sedıments, Geochim Cosmochım. Acta, 57, 579-595, 1993

Thomson, J., N.C Higgs, T R.S. Wilson, I W. Croudace, G.J de Lange, and P.JM van Santvoort, Redistribution and geochemical behaviour of redox-sensitive elements around $\mathrm{S} 1$, the most recent eastem Mediterranean sapropel, Geochim Cosmochim. Acta, 59, 3487-3501, 1995

Trefry, $\mathrm{J} \mathrm{H}$, and $\mathrm{S}$ Metz, Role of hydrothermal precipitates in the geochemical cycling of vanadium, Nature, 342, 531-533, 1989.

Van Hoof, A.AM B J.H van Os, J.G. Rademakers, C G Langeress, and G.J. de Lange, A palaeomagnetic and geochemical record of the upper Cochitı reversal and two subsequent precessional cycles from Southern Sıcily (Italy), Earth Planet Sci. Lett., 117, 235-250, 1989.

Van Os, B J H , L.J. Lourens, F J Hilgen, and G J de Lange, The formation of Pliocene sapropels and carbonate cycles in the Mediterranean Diagenesis, dilution and productivity, Paleoceanography, 9, 601-617, 1994

Van Os, B J H, J J Middelburg, and G J de Lange, Possible diagenetic mobilisation of barium in sapropelic sediment from the eastern Mediterranean, Mar. Geol., 100, 125-136, 1991

Van Santvoort, P.J.M., G J de Lange, J Thomson, H Cussen, T.R.S. Wilson, M.D. Krom, and K. Strohle, Actıve post-depositional oxidation of the most recent sapropel (S1) in sediments of the Eastern Mediterranean, Geochrm. Cosmochm Acta, 60, 4007-4024, 1996.

Verosub, K L., and A P Roberts, Environmental magnetism: Past, present and future, $J$ Geophys Res, 100, 2175-2192, 1995.

Vezzoli, L, Tephra layers in Bannock Basin (eastern Mediterranean), Mar Geol., 100, 2134,1991

Wilson, T R.S., J. Thomson, S Colley, D.J. Hydes, N.C. Huggs, and J. Sørensen, Early organic diagenesis The significance of progressive subsurface oxidation fronts in pelagic sedıments, Geochm. Cosmochim Acta, $49,811-822,1985$.

Wilson, T.R S., J. Thomson, D.J. Hydes, S Colley, F Culkin, and J. Sørensen, Oxıdation fronts in pelagic sediments Dragenetic formation of metal-rich layers, Science, 232 , 972-975, 1986

M.J Dekkers and C.G Langereis, Paleomagnetic Laboratory, Institute of Earth Sciences, Fort Hoofddıjk, Utrecht University, PO Box 800211,3508 TA Utrecht Netherlands (e-mall langer@geof.ruu nl dekkers@geof ruu nl)

G J de Lange and PJ.M van Santvoort, Department of Geochemistry, Institute of Earth Sciences, Utrecht University, P O. Box 80021 3508 TA Utrecht, Netherlands (e-mail. gdelange@earth.ruu nl; patrick@earth.ruu.nl)

M. Paterne, Centre des Faibles Radioactıvité, Domaine CNRS, Av. De la Terrasse, 91198, Gif sur Yvette, France (e-mail pateme@cfr cnrs-gif.fr)

(Recelved May 17, 1996, revised April 19, 1997; accepted May 8, 1997 ) 